\title{
CONHECIMENTO E MEDO: FAUSTO A CAMINHO DA DANAÇÃO
}

\section{KNOWLEDGE AND FEAR: FAUST ON THE WAY TO DAMNATION}

https://doi.org/10.46551/2179679320200009

Ludmila Fonseca ludmiladamatta@gmail.com iD https://orcid.org/0000-0002-2195-188X

RESUMO: A Historia von D. Johann Fausten, de 1587, primeira versão impressa da famosa narrativa sobre a vida de Fausto, é uma obra alemã de cunho luterano que objetiva construir um exemplo negativo: o bom cristão, leitor do romance, deve entender as consequências da arrogância e da leviandade diante de Deus. O protagonista, Fausto, buscando conhecimento proibido ao homem, faz um pacto com o demônio, o que o condena à eterna danação no inferno. As formas e consequências do saber são questões centrais do romance e objeto de análise deste artigo, que busca responder qual conhecimento é almejado e realmente alcançado por Fausto e quais são as consequências do pacto. $O$ principal resultado da busca por saber é um protagonista dominado pelo medo, incapaz, por isso, de retornar à misericórdia divina, mesmo após arrepender-se.

PALAVRAS-CHAVE: conhecimento, medo, Luteranismo, Fausto.

ABSTRACT: The Historia von D. Johann Fausten, 1587, the first printed version of the famous narrative about Faust's life, is a German Lutheran work that aims to build a negative example: the good Christian, reader of the novel, must understand the consequences of arrogance and levity towards God. The protagonist, Faust, seeking knowledge forbidden to man, makes a pact with the devil, which condemns him to eternal damnation in hell. The forms and consequences of the knowledge are central issues of the novel and object of analysis of this article, which aims to answer which knowledge is sought and really achieved by Faust and what are the consequences of the pact. The main result of the search for knowledge is a protagonist dominated by fear, unable, therefore, to return to divine mercy, even after repenting.

KEYWORDS: knowledge, fear, Lutheranism, Faust.

A primeira versão impressa da história de Fausto, especialmente consagrada mais de dois séculos depois pela escrita de Goethe, foi publicada em 1587, em Frankfurt am Main, pelo editor Johann Spies. A Historia von D. Johann 
Fausten, ${ }^{1}$ de autor desconhecido, trata da vida de um mago que, em busca de conhecimento, faz um pacto com o demônio. Composta no momento da Confessionalização na Alemanha, a obra de cunho luterano deixa entrever muitos aspectos da tumultuada passagem entre Medievo e Modernidade. Apesar de trabalhar de maneira central ideias modernas, como a sede de conhecimento, 0 entendimento do mundo por meio da razão, a imagem do homem responsável por si mesmo e, muitas vezes, insubordinado à vontade de Deus, o romance tem diversos elementos que ainda remontam à Idade Média, como a apresentação de uma cartografia de afetos (em que esperança só existe em contraposição ao medo, por exemplo), não vindos de uma interioridade do sujeito, e dos espaços imaginários medievais, como o céu e o inferno.

O objetivo da narrativa, que se vende como uma história real - em consonância também com os romances medievais alemães -, parece se construir num exemplo negativo capaz de desencorajar todos aqueles que se interessavam por magia, pelo demônio, por conhecimentos proibidos. Exatamente por isso, e diferentemente do desfecho da maioria das versões posteriores, na Historia, Fausto não encontra a salvação; ele é condenado à eterna danação.

No presente artigo, pretende-se esclarecer qual conhecimento é desejado por Fausto, qual é o real saber por ele adquirido, e como isso serve ao propósito da obra de ilustrar de forma exemplar o destino daqueles que se viram contra a palavra de Deus, em uma época de passagem, marcada pelo conflito entre valores novos e tradicionais, entre o religioso e o mundano.

\section{O conhecimento desejado}

Fausto é especialmente inteligente, e isso é enfatizado desde o início da narrativa, quando ele ainda era apenas um filho de camponês. Seus pais, por perceberem sua grande capacidade intelectual, alegram-se pela possibilidade, oferecida por um tio, de o filho estudar na cidade. Entre 16 estudantes, Fausto alcança o título de Doctor Theologiae. Isso, entretanto, não seria suficiente para o

\footnotetext{
1 A edição da Historia usada no presente artigo é a organizada por FÜSSEL, Stephan; KREUTZER, Hans Joachin. (Org.), 2012.
} 
acadêmico, que, apesar de seu engenho e da sua memória, é arrogante e tolo. ${ }^{2}$

Os adjetivos usados pelo narrador, cuidadosamente escolhidos, revelam quais conhecimentos são vistos de modo positivo ou negativo. Até o momento em que se dedica aos estudos teológicos, Fausto é retratado de forma positiva, mas, quando seu interesse se volta para a magia, ele é um tolo. O protagonista, que já tem o conhecimento - mais que permitido - valoroso, deseja o proibido. Para o arrogante, os escritos sagrados não são suficientes.

O começo do segundo capítulo esclarece suas intenções de buscar o saber mágico:

[...] queria investigar todos os fundamentos do céu e da terra / pois sua curiosidade / liberdade e leviandade / provocaram-no tanto / que ele, em um dado momento, (pesquisou) algumas palavras / imagens / escritos e conjurações / para poder chamar o diabo diante de si $[\ldots] .^{3}$

Buscar conhecimento não é explicitamente proibido, quando se tem em vista o contexto luterano da obra. ${ }^{4} \mathrm{O}$ tipo de saber, as razões para buscá-lo e os meios usados em tal busca são, por sua vez, os fatores críticos. O excerto anterior esclarece qual a curiosidade de Fausto, qual o conhecimento almejado: investigar todos os fundamentos do céu e da terra.

Lutero, em seus escritos, cria uma separação rígida entre o conhecimento divino e o conhecimento da natureza, as ciências naturais, mas estas últimas não são necessariamente contrárias a Deus. O homem teria a permissão de investigar Natureza e Cosmo exatamente porque as ciências naturais não alcançam o divino, mas, em certa medida, ocupam-se de sua manifestação. ${ }^{5} \mathrm{O}$ limite entre proibido e indesejável é, todavia, tênue, já que é de menor valia o emprego de energia para conhecer algo além de Deus, cuja palavra é o único saber valoroso. Somente a Teologia seria realmente digna.

Claramente, o interesse de Fausto pelo conhecimento não é cristão e inocente. Mesmo antes do pacto com o demônio, ele se volta, muito além de para

\footnotetext{
${ }^{2}$ História, p. 14. Por se tratar de um livro de autor desconhecido, na Germanística, citamos assim, sem o autor, com a primeira palavra do título do livro - o que será feito ao longo de todo este artigo.

${ }^{3}$ HISTÓRIA, p. 15, tradução nossa.

${ }^{4}$ HEESEN (2009), p. 45.

${ }^{5}$ Ver o capítulo de Marina MÜNKLER (2013, p. 228-258) sobre o papel da curiosidade na Historia.
} 
a Astrologia e a Matemática, para a magia: "Dardaniae artes / Nigromantiae / carmina / veneficium / vaticinium / incantatio (...)" ${ }^{6}$ Fausto, teólogo, conhecedor profundo da Bíblia, quer um saber transcendental maior do que aquele disponível nos Escritos Sagrados. No trecho, "todas as razões do céu e da Terra", a palavra "todas" indica exatamente o passo para além dos limites e em direção ao proibido.

Para alcançar seu objetivo, Fausto escolhe uma maneira bastante singular. Ele evoca o demônio e propõe um pacto, em que certas exigências são feitas: conhecimento e poder sobre o diabo são os dois objetivos primeiros - e não podem ser realmente separados na fala do personagem.

Como resultado deste encontro com o mal, o mago escreve e assina a declaração do pacto. Fausto esclarece que deseja do demônio, Mephostophiles, explicações sobre aquilo que os humanos até agora não foram capazes de esclarecer. ${ }^{7} \mathrm{E}$ deixa claro também por que se decidiu pelo pacto: por não ter conseguido alcançar o conhecimento desejado apenas a partir de suas próprias observações dos elementos. É importante perceber como o autor luterano constrói, nesse momento, uma crítica à ideia da autonomia humana que começa a surgir no período.

Fausto apresenta uma sede de conhecimento que o aproxima dos humanistas: a palavra usada pelo mago, "speculieren" (de origem latina, "speculare"), significa observar, usar os próprios sentidos a fim de entender o objeto observado, confiando na própria capacidade de investigação. O pacto com o diabo é, por sua vez, a confirmação do oposto, a confirmação da impossibilidade de adquirir o saber desejado por meio das próprias capacidades de observação e reflexão. Nesse sentido, o artifício de que Fausto lança mão, o pacto, acentua a sua falta de autonomia e, por conseguinte, serve como crítica à confiança humanista em relação aos frutos da racionalidade.

Fausto, com o pacto com Mephostophiles, busca o sobre-humano, mas o resultado da busca será estar face a face com a própria - e humana - impotência.

\section{As limitações do diabo}

\footnotetext{
${ }^{6}$ Historia, p. 14.

${ }^{7}$ Historia, p. 22.
} 
A segunda questão que se impõe em relação ao papel do conhecimento na Historia é: o saber desejado pelo mago realmente é alcançado? Segue-se ao pacto, na primeira das três partes da obra, uma série de perguntas feitas por Fausto e direcionadas a Mephostophiles. O que o protagonista ainda não sabe é que a sua curiosidade não será jamais plenamente satisfeita.

A primeira pergunta feita por Fausto diz respeito a Lúcifer. Fausto deseja saber como ele foi expulso dos céus. Posteriormente, há ainda muitas perguntas sobre o inferno. O mago questiona sobre a substância, o lugar e a criação do inferno; sobre o regimento e o poder do diabo; sobre a aparência de Lúcifer, quando ainda habitava nos céus; sobre o governo, o conselho, a violência, o ataque, as tentativas e a tirania do demônio; sobre as dores do inferno e os sofrimentos dos condenados. A última pergunta difere-se um pouco mais das anteriores: Fausto quer saber o que Mephostophiles faria se fosse um homem.

As primeiras respostas do diabo são bastante curtas e pouco esclarecedoras. Mephostophiles dá apenas uma informação nova para o mago: "nós, demônios, também não podemos saber de que e como foi criado o inferno ou como ele foi construído por Deus, pois ele não tem final nem fundo. E esse é o meu curto relato". 8 Que Mephostophiles não é o demônio mais poderoso já se sabe desde o início da Historia, quando ele precisa retornar ao inferno para relatar a Lúcifer as condições impostas por Fausto antes de firmar o pacto. Nesse trecho, entretanto, não se trata de seu poder limitado, mas do conhecimento limitado de todos os demônios.

O conhecimento transcendental, que não é acessível aos homens, parece também não ser totalmente disponível aos demônios, ainda que claramente os limites destes últimos sejam alargados em relação àqueles humanos. É importante, além disso, perceber que Mephostophiles trata do inferno como criação divina, e isso permite traçar um paralelo: humanos e demônios não conseguem entender completamente o mundo em que vivem. Para os habitantes, o saber sobre a sua morada não é completamente acessível.

Quando, por sua vez, Fausto pergunta sobre a tirania do demônio,

\footnotetext{
${ }^{8}$ Historia, p. 30 (tradução nossa).
} 
Mephostophiles responde: "sobre isso, você não pode desejar de mim uma resposta, pois diz respeito à nossa clandestinidade, e eu não tenho permissão de chegar até aî". ${ }^{9}$ Aqui, a frustração de Fausto ganha ainda outros contornos: nesse caso, Mephostophiles dispõe, sim, do saber, mas não tem permissão para compartilhá-lo com um humano. O diabo dá ao mago alguma, mas nunca toda a informação. Nesse sentido, grande parte do conhecimento que é proibido à humanidade e acessível ao diabo continua sendo inalcançável para o mago. Ainda que seja grande o poder do demônio em relação aos homens, ele não o é em relação a Deus. E é aí que se dá uma revelação essencial da obra: enquanto Fausto, vaidoso, desafia Deus e quer transpor os limites humanos, Mephostophiles mantém-se dentro dos seus limites - também por Deus impostos - como demônio. Como todo bom cristão sabe, e ironicamente inclusive o próprio diabo, os poderes do mal são limitados diante da onipotência do princípio do bem. ${ }^{10} \mathrm{O}$ próprio Mephostophiles diz que, se fosse humano, não teria feito as escolhas equivocadas de Fausto, mas teria respeitado a lei de Deus.

Apesar de ter sido avisado pelo diabo que não receberia o saber transcendental ansiado, Fausto continua a perguntar sobre o inferno. Finalmente, ele recebe a seguinte resposta:

Senhor Fausto / suas perguntas e questionamentos sobre o inferno e o seu poder / você deveria abandonar / Querido, o que você está fazendo consigo mesmo? Mesmo que você conseguisse subir aos céus, eu te faria cair novamente ao inferno / porque você é meu / e pertence também a esta pocilga. ${ }^{11}$

Ao afirmar que não responderia à pergunta de Fausto porque isso angustiaria o mago, o demônio dá a última explicação sobre a sua impossibilidade de responder. A partir deste momento, ele simplesmente afirma que não deve essas explicações a Fausto - o que seria, no mínimo, questionável, já que, durante o pacto, Mephostophiles comprometeu-se a ser obediente como um servo. Abatido, o mago já não tem forças para contestar o demônio. É ele quem se cala e mostra-se obediente.

\footnotetext{
${ }^{9}$ Historia, p. 34 (tradução nossa).

${ }^{10}$ Ver AUTERI, 1997.

${ }^{11}$ HISTÓRIA, p. 36, tradução nossa.
} 
A impossibilidade do demônio de oferecer a Fausto o conhecimento almejado é, dessa forma, clara na primeira parte da obra. Mephostophiles procura explicar isso com diferentes argumentos: 1. Ele também não tem o conhecimento; 2. Ele não tem permissão de transmitir o conhecimento; 3. Ele se preocupa com Fausto, que poderia sofrer ao receber o conhecimento; 4 . Ele não tem nenhuma obrigação de dar informações ao mago.

É irrelevante se perguntar qual dessas possibilidades corresponde à verdade; de acordo com o narrador, uma das características do demônio é, a propósito, a grande capacidade de mentir. Muito mais importante aqui é perceber o que ainda não foi tratado claramente por estudiosos da Historia: ${ }^{12}$ o pacto com o diabo não supre realmente a necessidade de Fausto, que continua sem ter acesso ao saber por ele desejado, apesar de todas as iniciais promessas de servidão feitas pelo demônio.

\section{O conhecimento disponibilizado}

Apesar de Mephostophiles afirmar que não pode responder a tudo, isso não significa que ele não compartilha nenhum saber. Na segunda parte da obra, dá-se um jogo entre mago e demônio: Mephostophiles não dá a Fausto tudo o que ele realmente deseja, mas começa a fingir alguma boa vontade. Se a primeira parte da Historia diz sobre a impossibilidade (ou a má vontade) do diabo de dar acesso ao saber, a segunda mostra o seu poder - ao menos, de ilusão. Nesta parte, pode-se analisar de maneira mais exata qual o conhecimento realmente oferecido por Mephostophiles.

O mago pergunta ao diabo sobre os céus, a criação do mundo, o inverno e o verão e a forma dos espíritos. E, surpreendentemente, tudo é respondido, em oposição ao que acontece na primeira parte da obra. A exceção é, no entanto, a pergunta sobre o inverno e o verão, o único questionamento sem teor teológico e, por isso, desvalorizado pelo diabo: "Meu senhor Fausto, você, como estudioso da natureza, não pode observar o sol e ter uma resposta sem a minha ajuda?". ${ }^{13}$

\footnotetext{
${ }^{12}$ Uma revisão do assunto foi feita, por mim, no trabalho de mestrado "Furchtals Emotion des Antihelden: Der ängstliche Faustauf dem Weg zur Verdammnis".

${ }^{13}$ Historia, p. 46 (tradução nossa).
} 
Nesta segunda parte, entretanto, não há um protagonista mais satisfeito com a sua escolha pelo pacto. Ele recebe respostas, mas nem sempre acredita no que Ihe é dito: o diabo mente e Fausto, como teólogo, sabe disso. Se a fonte de conhecimento é o demônio, todo o saber tem que ser necessariamente colocado em dúvida, o que já deixa clara a armadilha do pacto. Também o leitor é constantemente avisado pelo narrador sobre a possibilidade de todas as informações serem falsas. Talvez o exemplo mais claro disso seja o capítulo sobre a criação do mundo.

O narrador, já no título, adverte o leitor de que o relato do demônio é falso. Fausto, por sua vez, simplesmente se recorda da gênese descrita na Bíblia e põe em dúvida as palavras de Mephostophiles. Ele não se atreve, entretanto, a questionar o diabo diretamente. O mago tem neste trecho uma nova revelação: ele não alcançará o conhecimento mesmo quando suas perguntas forem respondidas, porque não há verdades no dito por Mephostophiles, ainda que o diabo reforce: "como você viu, eu nunca menti pra você". ${ }^{14}$

É neste momento que o demônio começa a oferecer a Fausto uma outra possibilidade para alcançar saber: ele não descreve a Fausto a forma dos demônios, ele as mostra. O mago experiencia, com o próprio corpo, aquilo que seria inacessível ao homem. Muitos espíritos revelam a Fausto a sua aparência, assim como a sua capacidade de transmutação. Posteriormente, é dada ao mago a oportunidade de conhecer o inferno. Ali, ele cheira, ouve, toca, vê; ele conhece a morada dos demônios por meio de seus cinco sentidos. Tudo isso, entretanto, não serve para validar o saber proporcionado pelo diabo, já que Fausto, por fim, questiona se realmente experienciou tudo isso, o que é revelado pelo narrador: "Novamente, ele questiona se o diabo não haveria apenas feito um jogo de ilusões para seus olhos, o que era realmente verdade". ${ }^{15}$

Enquanto o narrador tem certeza de que o mago nunca esteve no inferno e teve sua confiança traída por Mephostophiles, Fausto apenas desconfia disso. A narrativa mostra que também os sentidos podem ser enganados, delineando-se novamente uma crítica ao Humanismo a partir dos questionamentos das capacidades humanas: os sentidos, que, aliados à razão, são os instrumentos

\footnotetext{
${ }_{14}^{14}$ Historia, p. 45 (tradução nossa).

${ }^{15}$ Historia, p. 55 (tradução nossa).
} 
usados para alcançar conhecimento e investigar o mundo, são fáceis de enganar.

As viagens feitas pelo mago com Mephostophiles são outras experiências sensoriais que têm lugar na narrativa. Voando, Fausto conhece muitas cidades e alcança o firmamento. Surpreende, todavia, que a realidade dessas viagens não seja questionada nem por Fausto nem pelo narrador. Pelo contrário, muitas vezes são usadas estratégias para suspender a descrença do leitor. Fausto vai, por exemplo, a Roma e ali rouba louças de prata do Papa, as quais, afirma o narrador, são encontradas após sua morte em sua casa. Convencer o leitor de que a história é real aumenta sua força exemplar.

Tais estratégias, entretanto, não contribuem para que o conhecimento adquirido por Fausto durante essas viagens ganhe valor. Em carta enviada a um colega de universidade em Wittenberg, o mago diz que tudo aquilo por ele vivenciado e narrado pode ser encontrado em livros. Ora, se o saber adquirido por Fausto já constava nos livros, as suas viagens podem valer ao máximo como comprovação daquilo já escrito, jamais como possibilidade de adquirir novo saber.

É preciso, por fim, esclarecer que quase todos os textos sobre as viagens de Fausto foram retirados de um famoso livro da época, Chroniken der Welt, de Schedel, enquanto aqueles relacionados às ciências naturais têm como fonte 0 Elucidarius. ${ }^{16}$ Ambas as fontes eram já vistas, no momento de publicação da História, como ultrapassadas. A América, por exemplo, já tinha sido descoberta, mas essa informação não existe nas Chroniken der Welt, que foram escritas um ano antes da chegada de Colombo à América. Quando Fausto escreve que conheceu todo o mundo, a América não é citada, mas apenas "Asiam / Aphricamvnn dEuropam". ${ }^{17}$ Elucidarius, por seu turno, foi escrito em 1090, e, nos quase 500 anos entre tal obra e o Faustbuch, muitos avanços foram feitos nos estudos de Astronomia e Astrologia, e os novos tratados já contavam com informações atualizadas. ${ }^{18}$

Nesse sentido, é possível perceber que a desvalorização do saber oferecido por Mephostophiles está presente em diversos níveis da narrativa. Quando Fausto duvida daquilo que Ihe é dito ou diz que o conhecimento adquirido

${ }^{16}$ Tais fontes foram reunidas por FÜSSEL e KREUTZER (2012) e publicadas em sua edição crítica da Historia.

${ }_{17}$ Historia, p. 58.

${ }^{18}$ MÜNKLER, 2013, p. 106. 
já consta nos livros, as informações dadas por Mephostophiles são questionadas no nível diegético. O mesmo acontece no nível extradiegético, quando o narrador caracteriza o diabo como mentiroso. E, por fim, pode-se inclusive supor que o leitor real era capaz de identificar o saber transmitido por Mephostophiles como ultrapassado.

\section{As consequências do pacto}

Se a busca de Fausto por conhecimento, na verdade, não tem como consequência o saber em si, por meio do pacto com o demônio, ele alcança, porém, reconhecimento. Para o mago como figura social, a sua relação com Mephostophiles serve como meio de ratificar a própria palavra. Assim como Fausto antes do pacto, a sociedade também crê que o diabo pode tornar acessível o saber transcendental. Fausto transforma-se, assim, em autoridade intelectual, além de tornar-se ainda mais renomado como bruxo. Até o último momento de sua vida, ele conta aos seus amigos e estudantes sobre a força e o poder de Mephostophiles, sem nunca mencionar os problemas da sua relação com o demônio. Na carta ao seu colega de universidade, por exemplo, ele enfatiza que a sua viagem ao firmamento foi possibilitada por poderes diabólicos e afirma não ser mais um semelhante ao colega. Depois do pacto com o demônio, ele não seria mais um Doctor Theologiae, mas um Physikus, um conhecedor das ciências naturais. Se o diabo não é realmente uma fonte de conhecimento, ele serve ao menos como instrumento de convencimento social.

Não somente o saber é importante para a sociedade, mas também as suas possibilidades de uso. Fausto é reconhecido por meio da prática de medicina e de magia. Como médico, ele salva a vida de um conde. Como mago, ele alcança talvez a sua maior honra, quando é convidado à corte do imperador, que deseja ver pessoalmente a aparência de Alexandre, o Grande, já há muito morto. Fausto, filho de camponês, é recebido entre nobres e eruditos.

Por sua vez, a segunda consequência do pacto com o demônio é o medo. Se, por um lado, o mago alcança glória e fama na sociedade, por outro lado, durante o seu contato com Mephostophiles, torna-se mais e mais amedrontado. $\mathrm{E}$ é assim que o diabo mantém o controle sobre a sua alma e consegue levá-la ao 
inferno. Enquanto figuras anteriores da literatura alemã fizeram um pacto com o demônio e se salvaram lutando contra o poder do mal, ${ }^{19}$ Fausto não consegue se livrar da influência do diabo porque não é capaz de superar o medo.

A transformação de figura destemida a figura amedrontada dá-se quando o mago tenta enfrentar o demônio pela primeira vez. A vida de Fausto em seus primeiros momentos em companhia do diabo é de diversão e relaxamento, sem nenhuma preocupação em relação ao inferno ou à danação. $O$ narrador a caracteriza como "epicurista", o que é especialmente significativo levando em conta que, na filosofia de Epicuro, a necessidade de evitar o medo da morte tem um papel central. Seria sábio aproveitar a vida, não temer a morte, para ser livre não somente do medo da morte, mas também do medo da vida. ${ }^{20}$

O estilo de vida epicurista, entretanto, termina no ponto em que Fausto anuncia o desejo de se casar - o casamento é um fundamento do Luteranismo.

Todas as portas pularam de seus lugares / enquanto sua casa se enchia de calor / como se fosse se reduzir a cinzas. D. Fausto tentou fugir / mas um homem o alcançou / o jogou de volta no escritório / (...) / e o fogo, para todo lado, caiu sobre ele / como se ele fosse queimar. ${ }^{21}$

Nesta cena, o susto do protagonista, que desiste imediatamente do plano das bodas, transforma-se em medo. A violência do diabo determina uma transformação em Fausto que, de epicurista, começa já em vida a ser torturado pelo temor. Não sem razão, após tal acontecimento, Fausto começa a questionar Mephostophiles sobre os demônios, sobre as habilidades do diabo. Ele sonha com o inferno.

A primeira experiência negativa com Mephostophiles e as posteriores informações sobre o inferno dão ao mago material para imaginar. Ele passa a conhecer o inferno e a violência do demônio e, com isso, consegue não apenas prever vagamente o seu futuro depois da morte do corpo, mas criar e recriar com riqueza de detalhes o seu destino no inferno. A imaginação e o medo são, nesse

\footnotetext{
${ }^{19}$ E vale aqui a comparação com a narrativa católica Mariechen Von Nymwegen, cuja personagem principal também faz um pacto com o demônio, mas consegue salvar-se a partir da sua fé na Graça de Deus e da interferência da Virgem Maria.

${ }^{20}$ EPICURO, 2002, p. 29.

${ }^{21}$ HISTÓRIA, 2012, p. 28, tradução nossa.
} 
sentido, faces da mesma tortura. ${ }^{22}$

Depois que Mephostophiles narra como Lúcifer foi expulso dos céus, surge em Fausto o primeiro sinal de arrependimento. Ele vai para a cama silencioso, chora e tem a consciência de que a sua danação está garantida, pois percebe que não tem a capacidade de crer na misericórdia de Deus. Temer a Deus e somente a Deus e acreditar em Sua Misericórdia e Graça é, segundo o contexto luterano, a única salvação da alma e o único caminho em direção ao paraíso. ${ }^{23}$

Aqui se entende ainda melhor a posição central do medo nesta cartografia de afetos desenhada pela obra. Enquanto a esperança - ou seja, a perspectiva de um bom futuro - de alcançar a Graça de Deus leva à salvação, é exatamente o seu negativo, o medo - ou seja, a perspectiva de um futuro ruim -, o que impossibilita a redenção. No contexto da obra, ter medo do diabo significa necessariamente não ter a devida fé em Deus.

Ainda tendo em vista esta cartografia, é preciso tratar de outro afeto. Tão logo o medo entra em cena, desencadeia-se também o desespero. A diferença entre medo e desespero existe em relação à certeza sobre o futuro: aquele que ainda não está convencido da inevitabilidade do mal vindouro teme; se a certeza existe, entretanto, desespera-se. ${ }^{24}$ Fausto, enquanto aprende com o demônio sobre a violência, traça o caminho emocional de um condenado: ele tem medo, perde a esperança, e entra em desespero.

O ciclo vicioso - ou o ciclo demoníaco, se se quiser usar a tradução da palavra em alemão Teufelskreis - dá-se pelo fato de que, desesperando, Fausto procura escapar de seu destino por meio do conhecimento. E, ao obter informações, novamente teme e novamente se desespera.

\section{0 conhecimento como falsa esperança: o último passo no caminho à danação}

Esta é uma mudança central no papel do conhecimento na obra: se, no início da narrativa, o objetivo de Fausto era alcançar saber transcendental, a partir

\footnotetext{
${ }^{22}$ Vale a leitura do estudo publicado por Andreas BÄHR (2013) sobre o medo como afeto no contexto religioso do período pré-moderno (Frühe Neuzeit).

${ }^{23}$ LUTERO, 1973, p. 2262.

${ }^{24}$ Historia, p. 60.
} 
do momento em que experiencia o medo do demônio, ele passa a acreditar que o conhecimento pode ser instrumento de salvação. O saber deixa de ser fim e torna-se meio.

Ele pensou no que fez / e achou que através de muitas discussões frequentes / perguntas e conversas com o demônio / poderia chegar ao ponto de alcançar o próprio melhoramento / 0 arrependimento e a abstinência / Mas foi inútil / pois o diabo o tinha capturado muito bem. ${ }^{25}$

As perguntas feitas por Fausto quando procura usar o conhecimento como meio de salvação são exatamente aquelas relacionadas ao poder e à violência do demônio, ao inferno. É também aí que Fausto pergunta a Mephostophiles se ainda teria tempo de salvar-se da eterna danação. $O$ diabo avisa que tais perguntas não o ajudarão a fugir de seu destino, mas, ao contrário, despertarão ainda mais arrependimento, desencorajamento e dor. E o aviso corresponde, dessa vez, à realidade.

A grande maioria das respostas do demônio às perguntas teológicas de Fausto são amedrontadoras. Apesar de Mephostophiles dizer continuamente que não responderia mais nada, ele continua a dar informações ao mago. E tais informações não são, geralmente, conhecimento especial, mas apenas relatos detalhados da maldade, da violência e da tirania dos diabos e do inferno. Mephostophiles conhece os afetos humanos e sabe exatamente o que fazer para guiar Fausto em direção à sua danação. Ele divide com o mago somente um saber capaz de distanciar progressivamente Fausto da Graça de Deus.

Dentre as experiências oferecidas a Fausto, a viagem ao inferno é aquela que esclarece melhor a intenção do demônio de transformar o conhecimento em medo, porque é neste momento que o medo, que existia, mas não tinha forma, torna-se específico. O inferno na Idade Média e ainda no século XVI era um significativo lugar imaginário. Imaginário não como parte da fantasia; ${ }^{26}$ ao contrário, como parte de uma realidade sólida. $O$ inferno e o céu eram realidades e influenciavam diretamente o cotidiano; eram molduras para as cenas mais terrenas. Ambos eram espaços em que as semânticas centrais da cultura e do

\footnotetext{
${ }^{25}$ HISTORIA, p. 36, tradução nossa.

${ }^{26}$ BÖHME, 2000, p. 64.
} 
extremo das emoções eram projetadas e experimentadas.

Na História, o inferno é, assim, realidade. Se o conhecimento transmitido por Mephostophiles serve especialmente como material para o poder imaginativo de Fausto e, dessa forma, para a criação do medo, o inferno é o mais exato mal futuro e, ao ser imaginado, ele é evocado e presencializado. O sofrimento da danação já começa em vida, enquanto Fausto teme, chora, é melancólico. ${ }^{27}$

O inferno, na viagem do mago, é apresentado especialmente como lugar de dores físicas. A alma não é mais do que um outro corpo, a que podem ser infligidas aflições eternas, como no caso de todos os condenados vistos vagando pelo inferno que, apesar de serem almas, entidades não-corporéas (Fausto inclusive não consegue tocá-los), sofrem a danação por meio de sensações físicas. $^{28}$

Mephostophiles, dessa forma, controla Fausto e seus afetos ao deixar claro, por meio da transmissão de conhecimento, o sofrimento físico pós morte. Toda demonstração de violência do diabo ainda na Terra é também um anúncio da futura dor no inferno. Todas as vezes que Fausto deseja virar-se contra a influência do demônio, ele se vê ameaçado por uma agressão coreografada, representante do terror vindouro. O mago pertence a Mephostophiles exatamente porque, no intuito de atrasar ao máximo a sua entrada definitiva no lugar de eterna danação, coloca-se diretamente nele.

Finalmente, é preciso tratar da cena da morte de Fausto, pois ela é o fecho perfeito para uma narrativa em que a alma aflita não reencontra o caminho da salvação e em que o corpo e a busca por saber representam valores menores. Na noite da morte, já previamente programada pelo diabo e avisada a Fausto, barulhos terríveis são ouvidos pelos estudantes do mago, vindos de seu quarto.

\footnotetext{
${ }^{27}$ Há muitos estudos profundos sobre a apresentação e o significado da melancolia em Fausto, entre eles, os trabalhos de Maria E. MÜLLER (1986) e Marina MÜNKLER (2011). Não é possível, ainda, tratar de melancolia no período sem citar o detalhado estudo de KLIBANKY, PANOFSKY e SAXL (1992).

${ }^{28}$ Historia, p. 55. A expressão física de dor, na obra, não é uma codificação de sentimento experienciado interiormente. Durante a experiência de Fausto no inferno, não há nenhuma indicação de emoções não ligadas ao corpo. Muito pelo contrário, é sempre enfatizado que os estímulos que causam a dor têm origem externa. No período pré-moderno, ainda como na ldade Média, os afetos são entendidos prioritariamente de maneira espacial e não como consequência de mundos internos individuais, como será o caso posteriormente. A expressão do afeto, no caso de Fausto, não é então uma representação secundária do sofrimento, mas sim o sofrimento em si, cuja consequência é o desespero, a falta de esperança em tudo aquilo que é bom.
} 
Os discípulos, entretanto, somente pela manhã, atrevem-se a ir até lá. Quando abrem a porta, as imagens são fortes. O cérebro, a representação da racionalidade, está colado na parede: o saber não trouxe qualquer salvação, e o demônio deseja que isso esteja claro e seja exemplar. A cabeça, totalmente destruída, tem seus pedaços espalhados pelo chão. Os olhos, com que o mago viu e analisou o mundo, e os dentes, com que comeu inclusive as refeições do Papa, de nada servem diante da implacabilidade de Mephostophiles. O resto do corpo, descartado, sem o menor valor, é encontrado junto às fezes dos animais. Com tal morte, começa a experiência de danação de Fausto que, todavia, não figura na narrativa. O leitor, porém, já foi preparado pelo narrador e é seguramente capaz de imaginar o repetido sofrimento físico a que Fausto, ainda hoje, está submetido no inferno.

\section{Referências}

AUTERI, Laura. L'empia de vianza: l'origine del mito di Faust nel Historia del 1587. In: Cultura Tedesca 7 (1997): 7-23.

BÄHR, Andreas. Furcht und Furchtlosigkeit. Göttliche Gewalt und Selbstkonstitution im 17. Jh. Göttingen: V\&R, 2013.

BÖHME, Hartmut. Himmel und Hölle als Gefühlräume. In: BENTHIEN, Claudia; FLEIG, Anne; KASTEN, Ingrid. (Org.) Emotionalität: Zur Geschichte der Gefühle. Köln: Böhlau, 2000, p. 60-80

EPICURO. Carta sobre a felicidade: A Meneceu. Tradução e apresentação de Álvaro LORENCINI e Enzo Del CARRATORE. São Paulo: UNESP, 2002.

FONSECA, Ludmila. Furcht als Emotion des Antihelden: Der ängstliche Faust auf dem Weg zur Verdammnis. (Dissertação). Universidade do Porto, 2014. Disponível em https://hdl.handle.net/10216/89088.

HEESEN, Kerstin te. Das Illustrierte Flugblatt als Wissensmedium der Frühen Neuzeit (Tese). Bochum, 2009.

Historia von D. Johann Fausten (1587). Editada por FÜSSEL, Stephan; KREUTZER, Hans Joachim. Frankfurt a.M.: Reclam, 2012.

KLIBANSKY, Raymond; PANOFSKY, Erwin; SAXL, Fritz. Saturn und Melancholie. Studien zur Geschichte der Naturphilosophie und Medizin, der Religion und der Kunst: Frankfurt a.M.: Suhrkamp, 1992.

LUTHER, Martin. Biblia: Das ist: Die ganze Heilige Schrifft / Deutsch / Auffs new zugericht. Passau, Berlin: Rogner \& Bernhard, 1972, 1973.

Mariechen von Nymwegen.In:CORDAN, Wolfgang. (Org.) Jedermann, Lanselot und Sanderein, Marienchen von Nymwegen (1517). Düsseldorf; Köln: Eugen 
Diederichs, 1944, p. 77-125.

MÜLLER, Maria E. Der andere Faust: Melancholie und Individualität in der "Historia von D. Johann Fausten". In: DVjs 60 (1986): 572-608.

MÜNKLER, Marina. Narrative Ambiguität: Die Faustbücher des 16. bis 18. Jahrhunderts. Göttingen: V\&R, 2011.

SCHILLING, Michael. Curiositas, Literatur und Buchmarkt in der Frühen Neuzeit. In: DÜLLO, Thomas; STANDKE, Jan. (Org.) Theorie und Praxis der Kulturwissenschaften. Berlin: Logos, 2008, p. 130-146.

Ludmila Fonseca é mestre (com bolsa do programa de mestrado internacional GLITEMA - German Literature in the European Middle Ages) e doutora (bolsista da Universidade de Palermo) com dupla titulação pela Universidade do Porto, em Portugal, e pela Università degli Studi di Palermo, na Itália, e com sanduíche em duas universidades alemãs, Freie Universität Berlin e Universität Stuttgart. Especialista em literatura pré-moderna (de 1450 a 1650), dedica-se especialmente aos estudos dos romances do século XVI, tendo escrito seu doutorado sobre a representação e a funcionalização do autocontrole em romances em prosa do período.

Recebido em 20 de abril 2020. Aprovado em 05 de maio de 2020. 